\title{
Vasikan uni hyvinvointitutkimuksissa
}

Ann-Helena Hokkanen ${ }^{1,2)}$, Laura Hänninen ${ }^{1,2)}$, Johannes Tiusanen ${ }^{3)}$ ja Matti Pastell ${ }^{1,3)}$

1) Helsingin yliopisto, Eläinten hyvinvoinnin tutkimuskeskus, PL 57, O0014 Helsingin Yliopisto

2) Helsingin yliopisto, Kliinisen tuotantoeläinlääketieteen laitos, PL 57, 00014 Helsingin Yliopisto

etunimi.sukunimi@helsinki.fi

3) Helsingin yliopisto, Agroteknologian laitos, PL 28, 00014 Helsingin Yliopisto

etunimi.sukunimi@helsinki.fi

\section{Tiivistelmä}

Riittävä uni on tärkeää vasikan hyvinvoinnille. Erityisen tärkeää uni ja lepo ovat nuorille kasvaville eläimille, joiden aivot kehittyvät vielä. Uni ja leporytmin muutokset ovat uusimpia hyvinvointia kuvaavia mittareita.

Tuotantotiloilla saattaa olla pikkuvasikan uneen merkittävä vaikutus, sillä epämiellyttävät ympäristöolosuhteet voivat heikentää unen laatua. Useat erilaiset ympäristötekijät vaikuttavat yksilön uneen, samoin kipu. Kivuliaan yksilön uni sirpaloituu ja kipu heikentää unen laatua, kun taas unen puute vahvistaa kipukokemusta. Tuotantoeläinten unesta ja kivusta ei ole tehty tieteellisiä tutkimuksia. Tähän asti vasikan unta on tuotantoympäristöissä voitu mitata vain kannettavalla EEG-laitteistolla tai tarkkailemalla eläinten käytöstä. EEG-laitteisto on kallis ja häiritsee eläintä. Käyttäytymistarkkailu puolestaan vie paljon aikaa. Tavoitteenamme oli kehittää langaton mittalaite, aktigrafi, vasikan unen mittaamiseen.

Kiinnitimme kevyen, langattoman kiihtyvyysanturin 10 vasikan kaulapantaan. Vasikat olivat alle 6 viikon ikäisiä ja ne pidettiin tutkimuksen ajan olkikuivitetussa ryhmäkarsinassa. Laite kiihtyvyyden kolmen akselin suhteen $25 \mathrm{~Hz}$ taajuudella ja 2 g:n mittausalueella. Videoimme vasikoiden käytöstä yhtäjaksoisesti 24 tunnin ajan ja rekisteröimme keskimääräisen päivittäisen keston kokonaisuniajalle sekä, vilkeunelle (REM) ja hidasaaltounelle (NREM) vasikan lepoasennoista käyttäen CowLog-ohjelmaa.

Alustavat tulokset ovat valmiina kuudelta vasikalta. Aluksi unta ennustava malli (SVM luokittelija) kehitettiin kolmella vasikalla ja mallin toimivuus testattiin kolmella muulla vasikalla. Lopulliset tulokset saadaan 10 vasikalta. Aktigrafidatasta unta ennustivat parhaiten mallissa keskimääräinen kiihtyvyys, kiihtyvyyden vaihtelu ja wavelet-varianssi. Mallin antamien ennusteiden ja käyttäytymistarkkailun tulosten eroavaisuutta verrattiin t-testillä.

Malli ennusti kokonaisuniajan $93 \pm 3 \%$ tarkkuudella sekä päivittäisen NREM- ja REM-unen määrän $89 \pm 9 \%$ ja $83 \pm 2 \%$ tarkkuudella. Kokonaisuniajassa sekä NREM- ja REM-unen kokonaiskestoissa ei ollut tilastollisesti merkitseviä eroja käyttäytymistarkkailun ja unta ennustavan mallin välillä (621 vs. $602 \mathrm{~min}, 351$ vs. $339 \mathrm{~min}, 316$ vs. $351 \mathrm{~min}$ ).

Kehitimme aktigrafin, jolla mitata vasikoiden unikäyttäytymistä langattomasti yhtä tarkasti kuin käyttäytymistä tarkkaillen. Laite mahdollistaa vasikoilla jatkuvan unimittauksen tuotantoolosuhteissa häiritsemättä eläintä.

Asiasanat: Vasikka, aktigrafi, hyvinvointi, kipu, uni 


\section{Johdanto}

Riittävä uni on tärkeää eläinten terveydelle ja hyvinvoinnille. Erityisen tärkeää se on kasvaville eläimille (Siegel, 2005). Uni säätelee useiden hormonien kuten kasvuhormonin eritystä (Steiger, 2002) ja on välttämätöntä aivojen kehitykselle (Siegel, 2005). Vasikoiden hyvinvointitutkimus sekä tutkimukset vasikoiden unesta ja kivusta ovat tärkeitä, sillä tieteellistä tietoa nuorten tuotantoeläinten kivun kokemuksesta ja merkityksestä niiden myöhemmälle kehitykselle ei toistaiseksi ole olemassa.

Hyvinvointia tieteellisesti mitattaessa selvitetään mm. minkä biologisen hinnan yksilö maksaa ympäristöön sopeutumisestaan (Broom, 1988). Uni- tai aktiivisuusrytmejä voi mahdollisesti käyttää eläinten ympäristöön sopeutumisen mittarina (Ruckebush 1975, Scheibe ym., 1999, Veissier ym., 1989). Pikkuvasikoiden lepoaika, lepojaksojen pituus ja lukumäärä ovat kuitenkin hyvin stabiileja, eivätkä sen vuoksi toimi herkkinä ympäristöperäisen stressin mittareina (Hänninen ym., 2003, Hänninen ym., 2005). Ruckebush ehdotti jo 1975, että unijaksojen lukumäärä tai pituus voisi ilmentää vasikoiden ympäristöön sopeutumista.

Tuotantotiloilla saattaa olla pikkuvasikan uneen merkittävä vaikutus, sillä epämiellyttävät ympäristöolosuhteet voivat heikentää unen laatua. Useat ympäristötekijät, kuten vasikoiden siirtely, lattiamateriaali ja seura vaikuttavat vasikoiden uneen (Hänninen 2007). Unta voidaan myös hyödyntää vasikoiden kivun tutkimisessa. Nuorten tuotantoeläinten kivunhoitoon tulisi kiinnittää entistä enemmän huomiota, sillä nuoret eläimet ovat erityisen herkkiä kivulle. Nuorilla jyrsijöillä tehdyistä tutkimuksista tiedämme, että kehittyvät aivot ovat herkkiä erilaisten ympäristötekijöiden vaikutukselle ja varhaiset kokemukset muokkaavat yksilön myöhempää käyttäytymistä ja stressinsietokykyä (Anand ym., 1999). Syntymän jälkeisten viikkojen aikana kehittyvät aivot ovat alttiina ympäristön ärsykkeille ja varhaisessa kehitysvaiheessa koettu voimakas tai toistuva kipu muokkaa yksilön myöhempää kipukokemusta (Ruda ym., 2000). Kipu myös vaikuttaa uneen. Kivun voimakkuus näkyy unen sirpaloitumisessa (Bonnet \& Arand, 2003), mutta kivun ja unen suhde on kahtalainen; kipu heikentää unen laatua ja unen puute voi puolestaan vahvistaa kipukokemusta (Lavigne ym., 2005).

Tähän asti vasikan unta on tuotantoympäristöissä voitu mitata vain kannettavalla EEGlaitteistolla tai tarkkailemalla eläinten käytöstä (Hänninen ym., 2008). Hännisen ym. (2008) tutkimuksessa kehitettiin vasikoiden unelle ja unen kahdelle eri vaiheelle (REM ja NREM uni) toimivat käyttäytymismittarit. Nämä käyttäytymiseen perustuvat uniestimaatit mittasivat vasikoiden päivittäisen unen määrän ja eri unenvaiheissa vietetyn ajan samalla tarkkuudella kuin perinteinen unen sähköinen rekisteröintitapa (Hänninen, 2007). Unikäyttäytymisestimaattien haittapuolena on aikaa vievä rekisteröiminen videoilta; yhden vasikan vuorokauden unirytmin rekisteröimiseen kuluu kokeneelta tarkkailijalta noin 5 tuntia työaikaa. Myös videokameroiden sijoittelu eläintiloihin on ajoittain haastavaa, joskus mahdotonta. Ihmisten unen rekisteröimiseen on käytetty aktigrafia eli ranteeseen tai nilkkaan kiinnitettäviä aktiivisuusmittareita, jotka on validoitu osoittamaan milloin koehenkilö on unessa (Lötjonen ym., 2003).

Tavoitteenamme oli kehittää langaton mittalaite, aktigrafi, vasikan unen mittaamiseen. Laitteen tarkoituksena on helpottaa ja nopeuttaa vasikoiden aktiivisuuden ja unen tutkimista erilaisissa tuotantoympäristöissä eläimiä häiritsemättä.

\section{Aineisto ja menetelmät}

Kehittääksemme vasikan unta automaattisesti mittaavan laitteen, kiinnitimme kevyen, langattoman kiihtyvyysanturin 6 vasikan kaulapantaan. Vasikat olivat alle 6 viikon ikäisiä länsisuomenkarjan vasikoita ja ne pidettiin tutkimuksen ajan olkikuivitetussa ryhmäkarsinassa, jonka pinta-ala oli $17,5 \mathrm{~m}^{2}$. Vasikat saivat vapaasti automaatista (vasikkapiika, Finnlacto) AIV 2- liuoksella hapatettua juomarehua (Startti Instant, Valio) sekä hyvälaatuista säilörehua ja väkirehua. Vasikoiden hoito ei poikennut tilan normaalista käytännöstä tutkimuksen aikana.

Videoimme vasikoiden käytöstä yhtäjaksoisesti 24 tunnin ajan ja rekisteröimme keskimääräisen päivittäisen keston kokonaisuniajalle sekä vilkeunelle (REM) ja hidasaaltounelle (NREM) vasikan lepoasennoista (Hänninen ym., 2008, kuvat 1 ja 2) käyttäen tarkoitusta varten kehitettyä CowLog-ohjelmaa (Hänninen \& Pastell 2009).

Kiihtyvyysanturi ja siihen yhdistetty pieni paristo painoivat yhteensä $19 \mathrm{~g}$. Pienen laitteen (15 x 36 x $34 \mathrm{~mm}$ ) ei voitu todeta häiritsevän eläintä. Laite rekisteröi liikkeen ja kiihtyvyyden kolmen akselin suhteen $25 \mathrm{~Hz}$ taajuudella ja 2 g:n herkkyydellä. Kiihtyvyysanturin tieto lähetettiin langatto- 
masti radion välityksellä tietokoneelle, johon data tallennettiin. Mittalaite on esitelty yksityiskohtaisesti artikkelissa Pastell ym., (2009).

Laskimme mittausaineistosta keskiarvon, varianssin ja wavelet-varianssin (5 osaa) 20 sekunnin osissa ja saimme 7 muuttujan piirrevektorin jokaiselle ajanjaksolle. Opetimme support vector machine (SVM) luokittelijan piirrevektoreiden ja videolta koodatun käyttäytymisen avulla. Mallin opetuksessa käytettiin 3 vasikan aineistoa ja malli validoitiin 3:n eri vasikan aineistolla. Mallin antamien ennusteiden ja käyttäytymistarkkailun tulosten eroavaisuutta verrattiin t-testillä.

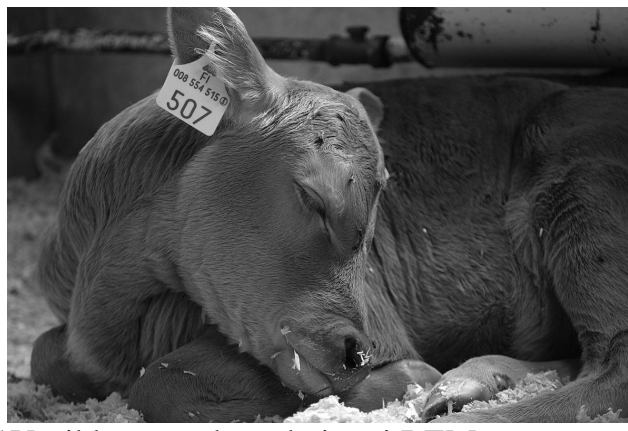

Kuva 1Vasikka on todennäköisesti REM-unessa, kun se makaa hiljaa paikoillaan, pää taivutettuna vähintään 30s ajan (Hänninen ym. 2008).

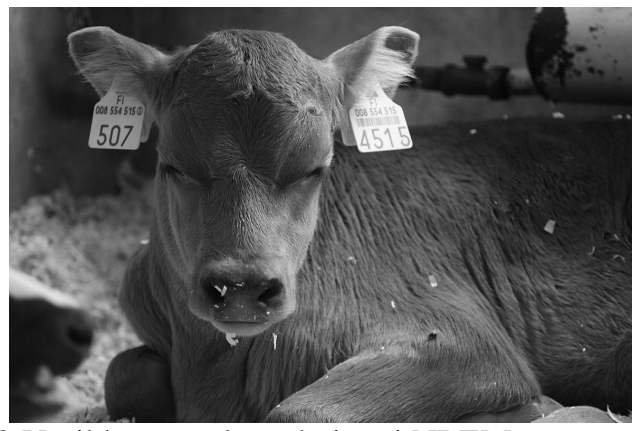

Kuva 2 Vasikka on todennäköisesti NREM-unessa, kun se makaa hiljaa, pää pystyssä vähintään 30s ajan (Hänninen ym. 2008).

\section{Tulokset ja tulosten tarkastelu}

Malli ennusti kokonaisuniajan $93 \pm 3 \%$ tarkkuudella sekä päivittäisen NREM- ja REM-unen määrän $89 \pm 9 \%$ ja $83 \pm 2 \%$ tarkkuuksilla. Kokonaisuniajassa sekä NREM- ja REM-unen kokonaiskestoissa ei ollut tilastollisesti merkitseviä eroja $(p>0,05)$ käyttäytymistarkkailun ja unta ennustavan mallin välillä kolmella validointiin käytetyllä vasikalla (621 vs. 602 min, 351 vs. 339 min, 316 vs. $351 \mathrm{~min})$.

Päivittäinen makuuaika laskettiin mallin antamien ennusteiden ja käyttäytymistarkkailun tulosten perusteella ja näiden eroavaisuutta verrattiin t-testillä. Malli ennusti kokonaismakuuajan $97 \pm 1$ $\%$ tarkkuudella. Kokonaismakuuajassa ei ollut tilastollisesti merkitseviä eroja $(\mathrm{P}>0,05)$ käyttäytymistarkkailun ja makuuaikaa ennustavan mallin välillä kolmella validointiin käytetyllä vasikalla (990 vs. $984 \mathrm{~min})$.

\section{Tulosten tarkastelu ja johtopäätökset}

Kehitimme aktigrafin, jolla mitattiin vasikoiden unikäyttäytymistä langattomasti yhtä tarkasti kuin käyttäytymistä tarkkaillen. Laite mahdollistaa vasikoilla jatkuvan unimittauksen tuotantoolosuhteissa häiritsemättä eläimiä ja vaikuttamatta niiden normaaliin käytökseen. Malli pystyi ennustamaan hyvin kokonaisuniajan sekä REM- ja NREM-unen kestojen lisäksi seisomisen, ja lepäämisen kokonaiskestot. Laitteen avulla voidaan tehostaa vasikoiden hyvinvoinnin tutkimusta ja saada arvokasta lisätietoa eläinten käyttäytymisestä. Laite mahdollistaa vasikoiden käyttäytymisen tutkimisen myös olosuhteissa, joissa kameroita ei voida käyttää.

Tuotantoeläinten unesta ja kivusta ei juurikaan ole tehty tieteellisiä tutkimuksia. Laitetta käytetään jatkossa hyväksi vasikoiden nupoutuskipututkimuksessa, jossa tarkoituksenamme on selvittää vasikoiden kipukäytöstä sekä kipulääkkeen tarvetta nupoutuksen. Pyrimme siis hyödyntämään laitetta vasikoiden unen mittaamista kipukäyttäytymisen tutkimisessa.

\section{Kirjallisuus}

Anand, K., Coskun, V., Thrivikraman, K., Nemeroff, C. \& Plotsky, P., 1999, Long-Term Behavioral Effects of Repetitive Pain in Neonatal Rat Pups, Physiology \& Behavior, 66: 627-637.

Bonnet M. \& Arand D. 2003 Clinical effects of sleep fragmentation versus sleep deprivation. Sleep Medicine Reviews 7: 297-310.

Broom D M., 1988, The scientific assessment of animal welfare. Appl Anim Behav Sci 20: 5-19.

Hänninen, L. \& Pastell, M. 2009. CowLog: Open source software for coding behaviors from digital video. Beh. Res. Met. 41: 472-476. 
Hänninen, L. Mäkelä, J.P., Rushen,J., de Passillé, A.M. \& Saloniemi, H., 2008. Assessing sleep state in calves through electrophysiological and behavioural recordings: A preliminary study, Appl. Anim. Beh. Sci. 111:235-250.

Hänninen L, de Passillé A M \& Rushen J. 2005. The effect of flooring type and social grouping on the rest and growth of dairy calves. Appl Anim Behav Sci 91: 193-204.

Hänninen, L., Hepola, H., Rushen, J., de Passillé A M, Pursiainen P, Tuure, V. M, Syrjala-Qvist, L, Pyykkonen M \& Saloniemi H. 2003. Resting behaviour, growth and diarrhoea incidence rate of young dairy calves housed individually or in groups in warm or cold buildings. Acta Agriculturae Scandinavica Section A-Animal Science 53: 21-28.

Hänninen L. 2007, Sleep and rest in calves - relationship to welfare, housing and hormonal activity. University of Helsinki http://ethesis.helsinki.fi/julkaisut/ela/kliin/vk/hanninenDoctoral Dissertation. 78s.

Hänninen, H., Hepola. H., Raussi. S. \& Saloniemi, H., 2007. Effect of colostrum feeding method and presence of dam on the sleep, rest and sucking behaviour of newborn calves, Appl. Anim. Behav. Sci, 112; 213-222 .

Hänninen, L., Kaihilahti, J., Taponen, S., Hovinen, M., Pastell, M. \& Pyörälä, S., 2007. Does behaviour predict acute endotoxin mastitis in dairy cows?, Proceedings of the $41^{\text {st }}$ International Congress of the ISAE, p. 58., Merida, Mexico.

Kaihilahti, J., Hyvärinen, E., Ruskanen, I., Raussi, S., Hyttinen, J., Lensik, J. \& Vainio, O. 2006. Ambulatory tool for cardiac activity measurements in animal research. Proceedings of the 4th International Congress of ISAE, 8.-12.8.2006 Bristol, England, s. 231

Kupers, R. \& Gybels, J. 1995. The consumption of fentanyl is increased in rats with nociceptive but not with neuropathic pain. Pain 60: 137-141.

Lavigne, G., McMillan, D. \& Zucconi, M. 2005. Pain and sleep. teoksessa Principals and practice of sleep medicine. (toim.) .Kryger MH, Roth T, Dement W). Elsevier Saunders, 4: 1246-1255.

Lotjonen, J., Korhonen, I., Hirvonen, K., Eskelinen, T., Myllymaki, M. \& Partinen, M. 2003. Automatic sleep-wake and nap analysis with a new wrist worn Online activity monitoring device Vivago WristCare (R). Sleep 26: 86-90.

Pastell, M., Tiusanen, J., Hakojärvi, M. \& Hänninen, L. 2009. A wireless accelerometer system with wavelet analysis for assessing lameness in cattle, Bios. Eng. doi:10.1016/j.biosystemseng.2009.09.007

Ruckebush Y. 1975.The hypnogram as an index of adaptation of farm animals to changes in their environment. Applied Animal Ethology 2: 3-18.

Ruda, M., Ling, Q., Hohmann, A., Peng, Y. \& Tachibana T. 2000. Altered Nociceptive Neuronal Circuits After Neonatal Peripheral Inflammation. Science 2000; (289): 628-630.

Scheibe, K. ., Berger, A., Langbein, J., Streich, W. \& Eichhorn, K. 1999. Comparative analysis of ultradian and circadian behavioural rhythms for diagnosis of biorhythmic state of animals. Biological Rhythm Research 30: 216-233.

Siegel, J.M., 2005. Clues to the functions of mammalian sleep. Nature 437, 1264-1271.

Stafford, K. \& Mellor, D. 2005. Dehorning and disbudding distress and its alleviation in calves. The Veterinary Journal 169: 337-349.

Steiger, A., 2002. Sleep and the hypothalamo-pituitary-adrenocortical system. Sleep Med. Rev. 6:125-138. Sutherland, M., Mellor, D., Stafford, K., Gregory, N., Bruce, R. \& Ward, R. 2002. Cortisol responses to dehorning of calves given a 5-h local anaesthetic regimen plus phenylbutazone, ketoprofen, or adrenocorticotropic hormone prior to dehorning. Research in Veterinary Science 73: $115-123$

Veissier, I., Neindre, P., Trillat, G. \& Le-Neindre, P. 1989. The use of circadian behaviour to measure adaptation of calves to changes in their environment. Appl Anim Behav Sci 22: 1-12. 